\title{
DRIVING FORCES AND INHIBITORS OF SECONDARY STOCK EXTRACTION
}

\author{
Anders Kihl, M. Sc. Environmental Engineering ${ }^{1}$ \\ Graham Aid, Tekn. Lic.. Industrial Ecology ${ }^{2}$ \\ ${ }^{1} R \& D$ Manager, Ragn-Sells $A B$, \\ ${ }^{2} P h . D$. Candidate LiU, Sweden \& R\&D Engineer Ragn-Sells $A B$, \\ Sweden
}

\begin{abstract}
Even though it's well known to mankind that our common resources are limited and that recycling is a key for a sustainable future; in reality we see few examples of true recycling where virgin raw material is substituted by waste. There are endless number of examples where waste is utilized to some extent without solving the core issue: reducing the need of extracting virgin raw materials. This article analyses some of the driving forces and inhibitors that explains why it's so difficult establish secondary stock extraction although technology is available. The authors discuss and suggest possible ways for reducing the some of the main barriers.
\end{abstract}

Keywords: Resources, Recycling, Economy, Sustainability, Circular Economy

\section{Introduction}

The consumption of raw materials fueling the world economy is staggering; some 65 billion tones (9.5 tones per capita) entered the economic system 2010 and is estimated to grow to about 82 billion tones (10.6 tones per capita) by 2020[1]. The surge for raw materials is driven by economic growth in the world. For example, in Sweden per capita material use is already over 15 tons per capita[2]. By 2030 up to 3 billion more middle-class consumers are expected in the world [3]. As prices for raw materials are expected to increase due to higher demand more diluted or remote deposits will be possible to extract. The more diluted and/or remote deposits are used the more waste is produced, energy is exerted, and economic resources required per unit produced resource. It is in such situations that high value material recycling become ever more viable.

\section{Problem formulation}

Current waste management practice is focused on dealing with a waste problem i.e. the cheapest way to safely get rid of the problem rather than bringing uncontaminated resources within waste back to the same production and consumption loop in several iterations.

All recycling activities are not equal in regards to 1) retaining clean material streams, and 2) ensuring economic and technical viability of future recycling iterations. For example the use 
of incinerator slags for road construction will deeply reduce the viability of extracting secondary resources from such constructions in the future.

Those recycling activities that excel at 1) retaining a clean material streams, and 2) ensuring economic and technical viability of future recycling iterations are not always technically and/or economically viable today. However, there is a large probability that they will be viable in the near future. Issues behind the viability of secondary stock extraction is expanded upon in the next section.

\section{Viability of Secondary Stock Extraction (now and in the future)}

As a goal of high value waste management and recycling activities is to substitute virgin materials in valuable (original) applications, the viability of extracting secondary stock is highly coupled to the market value of the virgin stock it will substitute and the value of alternative markets for the secondary materials (of which the material is being extracted).

\section{Market value for Virgin (Primary) Stock}

The market value of virgin stock, among other aspects, depends on 1) Supply, including cost for virgin extraction and total market supply, and 2) Demand, including total market demand, elasticity of demand in relation to price, and the availability of substitute materials.

\section{Alternative market value for the secondary materials}

When assessing the viability of secondary stock extraction, alternative pathways for recycling or treating the raw secondary materials (those materials from which the secondary stock may be extracted). Alternative market pathways could be, for example, use as ballast material, landfilling, use as recycled fuels, etc. These alternative pathways may have a negative or positive economic value, and may or may not incur substantial processing costs.

\subsection{Virgin Stock Extraction}

Virgin stock extraction efficiency depends on availability (scarcity), economies of scale, material concentration (for example ore grade), and technological efficiency (including energy demand), among other aspects. It is increasingly apparent that for several critical virgin resources around the world that availability and material concentration are reducing. See Figure 1 for an example of copper ore grades over time. 
Linnaeus Eco-Tech'14

Kalmar, 24-26 November, Sweden

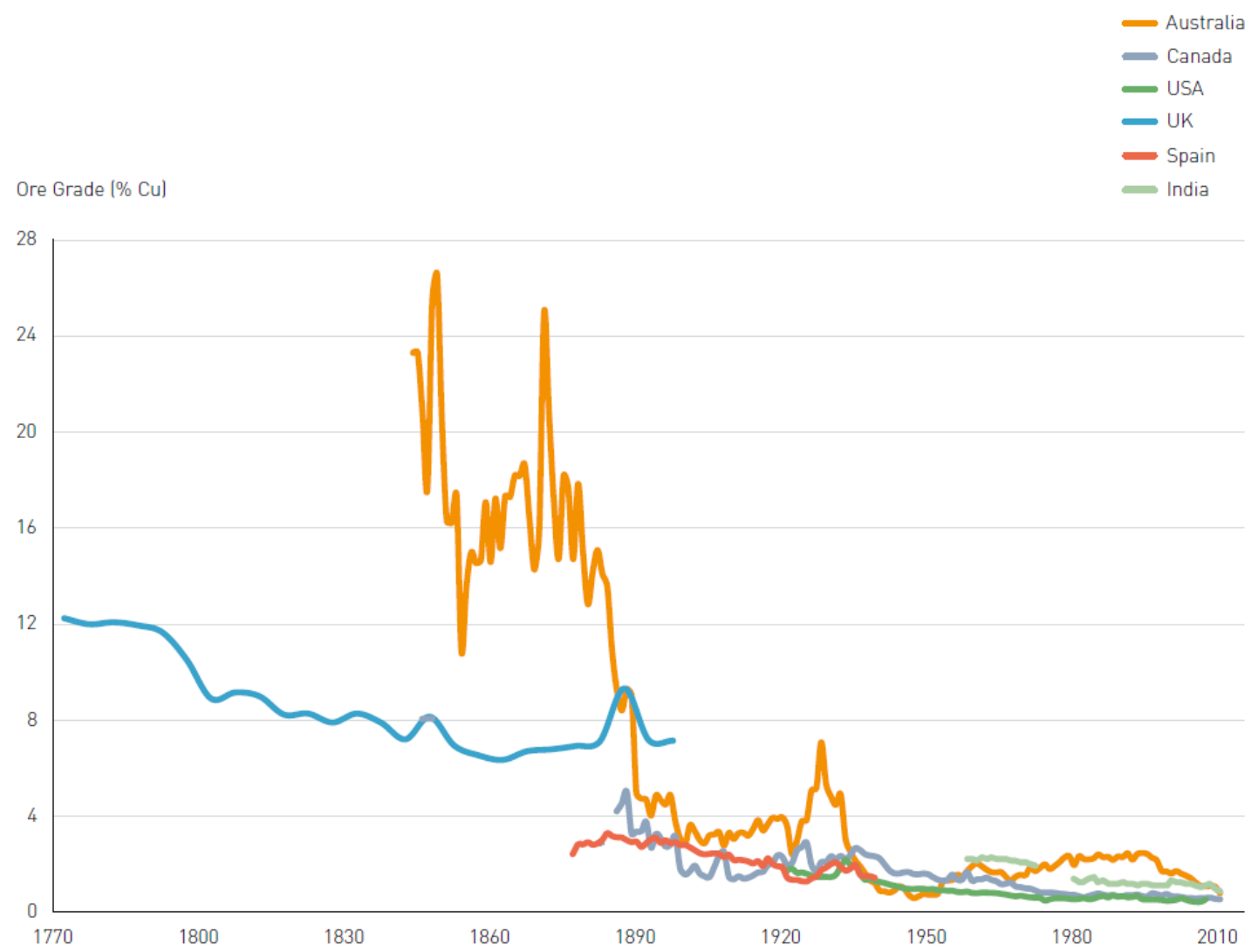

Figure 1- Long-term trends in processed copper ore grades for select countries (data from Crowson, 2012; Mudd, 2010a, Mudd, 2010b; Ruth, 1995; USBoM, var.; USGS, var.) table from from [3]

These availability and material concentrations are inter-coupled and impact technological efficiency and energy use. See Figure 2 for an example of the increased energy demand for $\mathrm{Cu}$ production as ore grade diminishes. 


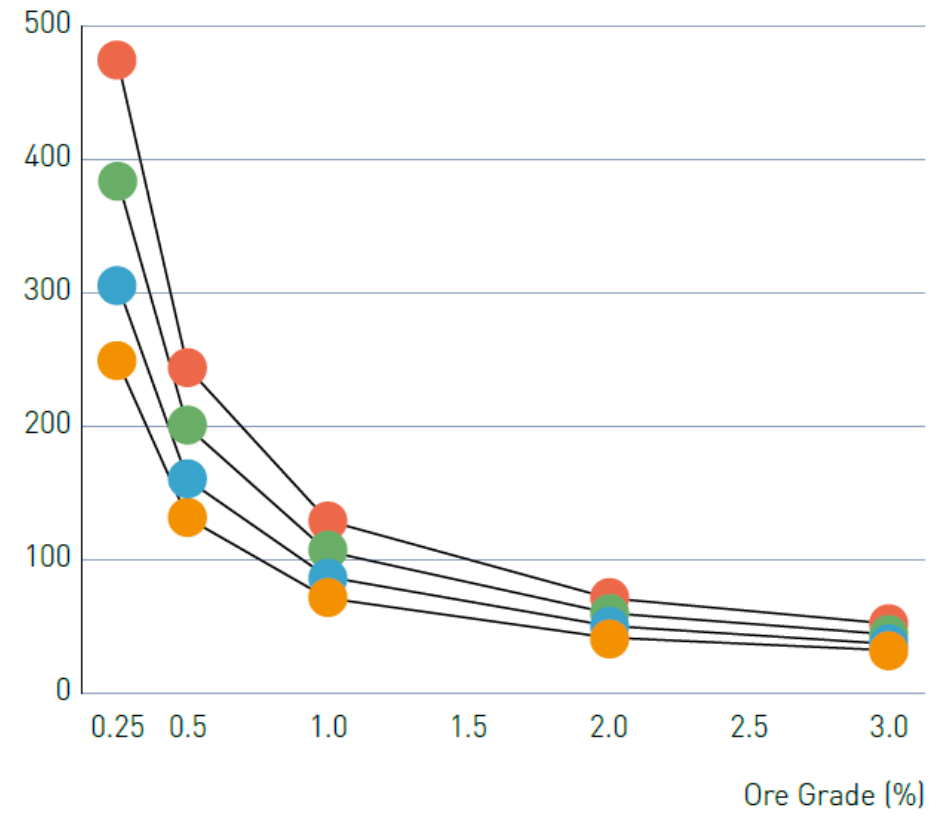

Figure 2- Effect of ore grade and liberation size on embodied energy for copper production [4] Figure from [3]

\subsection{Cost of Stock Extraction Over Time}

Given the assumptions that 1) available virgin ore grade over time is decreasing, and in turn increasing the energy and overall cost to extract virgin materials and 2) technological development is steadily decreasing the cost for extraction of substances in secondary stocks; we have prepared Figure 3 as an illustrative example. While in reality, the curves for extraction costs may be more or less dramatic depending on factors such as technological development (virgin and secondary). However, the cost trends are currently headed in this general direction [3][5][6].

Secondary stock extraction is not necessarily viable when the trend curves intersect in Figure 3. The point at which secondary stock extraction is viable is illustrated further in Figure 4 looking at market values. 
Linnaeus Eco-Tech'14

Kalmar, 24-26 November, Sweden

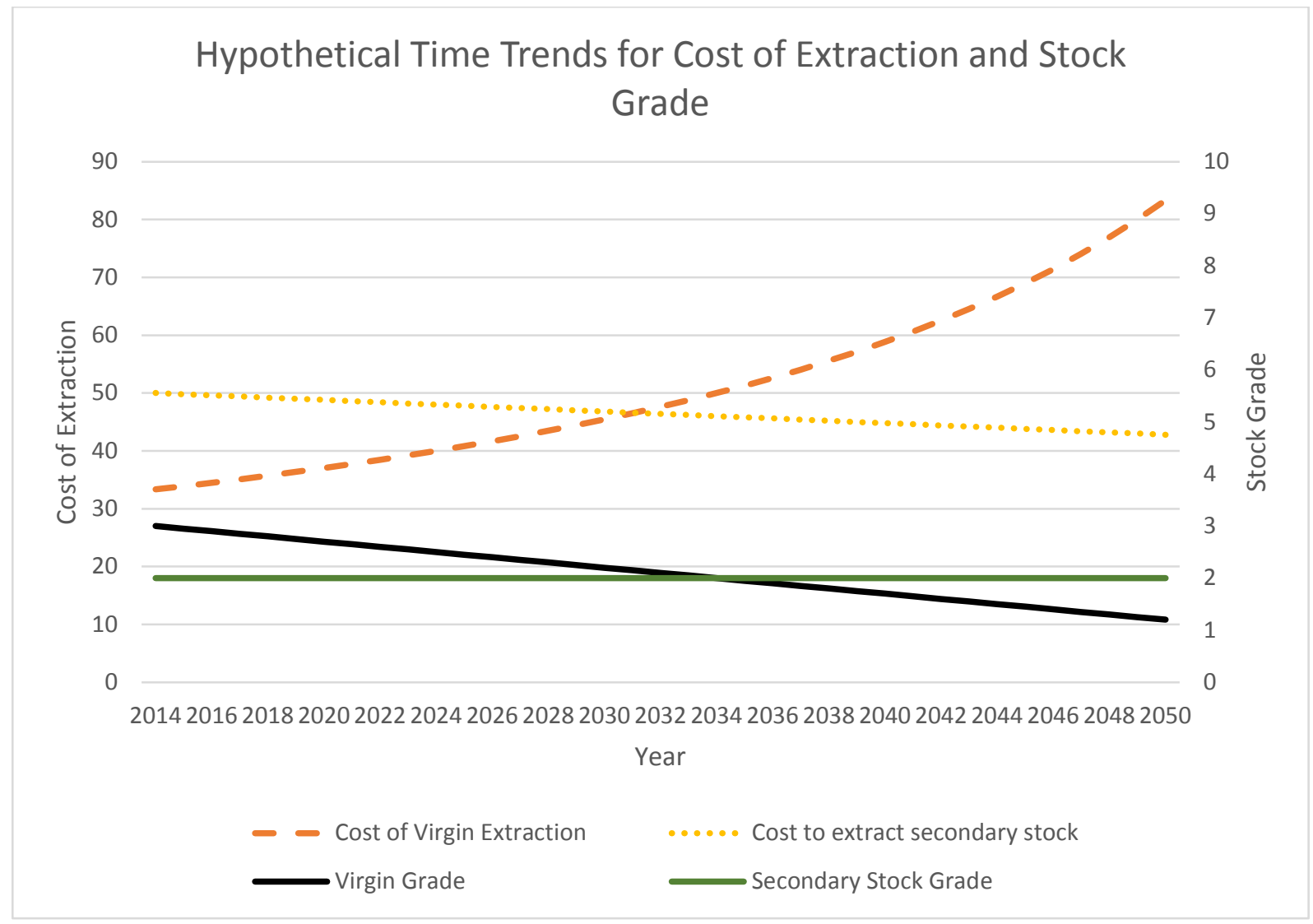

Figure 3 - The Hypothetical Time Trends for Cost of Virgin and Secondary Stock extraction along with material grade

\subsection{Markets Alternatives for Raw Secondary Stock}

Waste materials and by-products are a resource with several alternative 'markets' or uses. These markets may be, for example, energy recovery, use as additives (such as ashes in stabilized soil), landfill, ballast material, etc. When deciding which pathway a waste resource will follow the responsible organization may compare the various markets, their value, and the related production costs in preparing the raw stock for such a market. Other aspects such as access to markets, legal ability including permits, and company strategy may also play a role. Figure 4, illustrates how a decision for performing secondary material extraction can be compared to alternative material markets. When the value of the virgin stock being substituted is higher, the viability of extracting secondary stock increases. The point at which extracting secondary stock is a preferential option compared to alternative material markets depends on the production (extraction) costs of the secondary stock. These costs vary depending on economies of scale, if landfilling costs are incurred in the stockpiling of secondary stock, etc. The circles in Figure 4 mark the point at which stock extraction is a competitive alternative to alternative markets. 


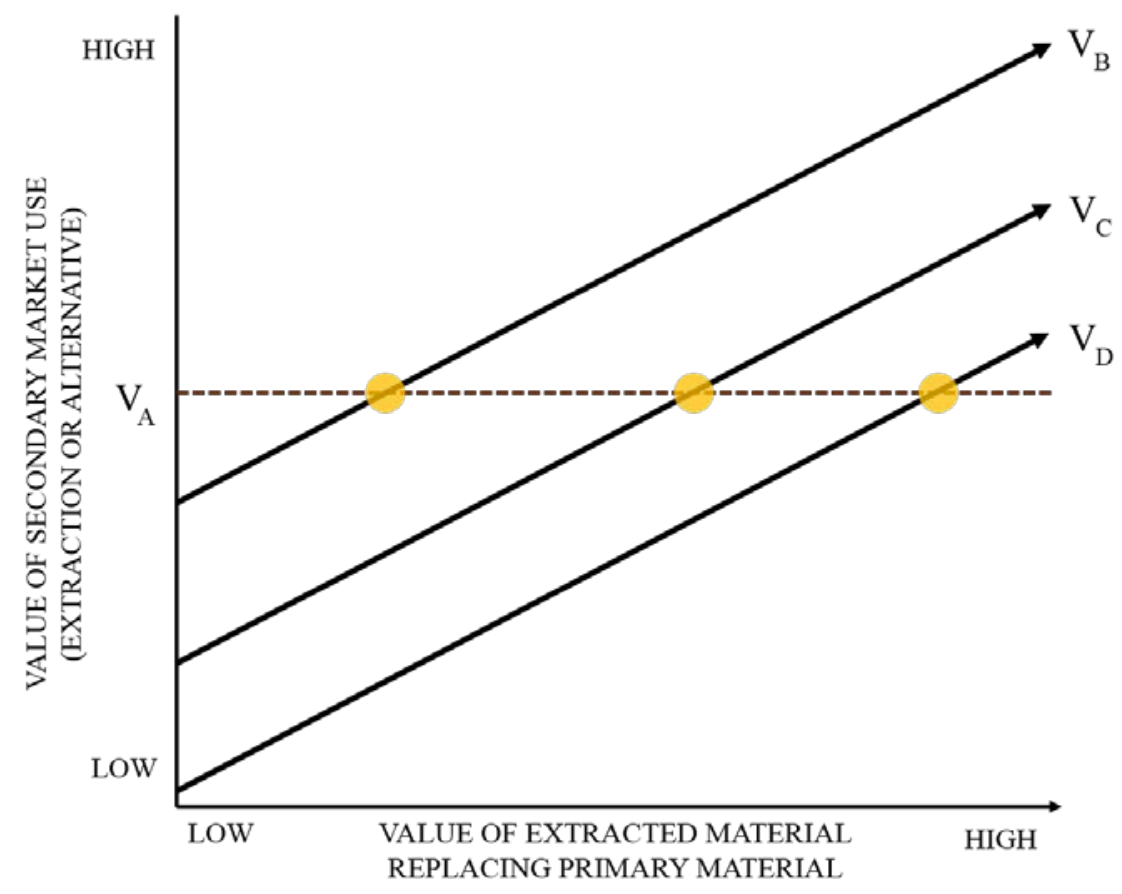

Figure 4 - The value of secondary stock extraction costs $\left(V_{B}, V_{C}, V_{D}\right)$ and the value of alternative recycling/treatment options $\left(V_{A}\right)$ in relation to the market value of substituted primary material (Horizontal axis).

$V_{A}=$ Market value of alternative recycling/treatment options such as road base aggregate, recycled fuel, landfilling, etc. after processing costs. These can have a positive or negative economic value.

$\boldsymbol{V}_{\boldsymbol{B}}, \boldsymbol{V}_{\boldsymbol{C}} \boldsymbol{\&} \boldsymbol{V}_{\boldsymbol{D}}=$ Value of extracting secondary stock after various production costs. $\boldsymbol{V}_{\boldsymbol{B}}=$ stock accumulation through longer term stockpiling allowing lower production cost, and no stockpiling fees (such as landfill tax).. $\boldsymbol{V}_{\mathrm{C}}=$ the stockpiling of material is not taxed as landfilling. $\boldsymbol{V}_{\boldsymbol{D}}=$ the stockpiling of material incurs landfilling fees, increasing the production cost.

One can also infer from Figure 4, that if $\mathrm{V}_{\mathrm{A}}$ (the value of alternative market delivery) were to go down via market forces or steering mechanisms (such as taxes on waste to energy or mixing into ballasts), that secondary material extraction would become competitive at even lower market values for the extracted material. Conversely, if new technologies, market forces, or steering mechanisms were to make alternative markets more valuable (less negative or more positive) it would take even higher extracted material values to enable extraction.

\subsection{Virgin Stock Criticality (Demand)}

It is not assumed that all secondary stocks will be suitable for viable extraction in the near future. However, some hints as to which materials may be more critical in the near future is given by the US Geological Survey and the McKinsey Global Institute [3] in Table 1. This table touches on many of the market drivers mentioned in the beginning of this chapter including: market supply (left columns), availability of substitutes to the virgin material, and key industrial demand (right two columns). Elasticity of demand is in turn related to availability of substitutes and key industrial demand. 


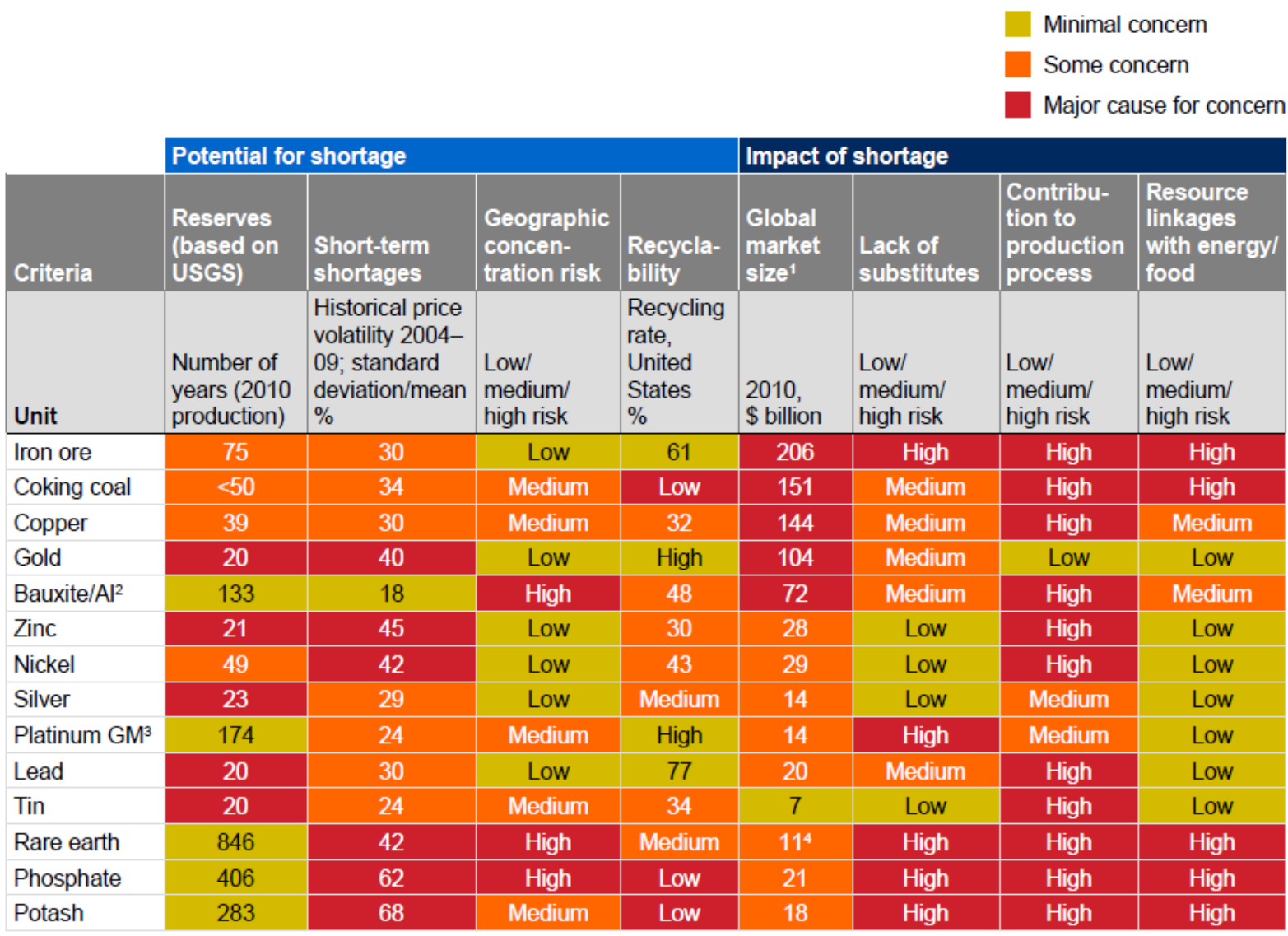

1 Wherever possible, market size represents finished/refined metal, e.g., market size is for aluminum metal and not alumina or bauxite.

2 Data for reserves and geographic risk pertain to ores (in this case, bauxite). Other data pertain to refined metal (in this case, aluminum)

3 Platinum group metals includes ruthenium, rhodium, palladium, osmium, iridium, and platinum and are grouped together because of their similar physical and chemical properties as well as tendency to occur together in the same mineral deposits.

4 Rare earth market size was only \$1 billion in 2009 but has spiked to \$11 billion in 2011.

As can been seen in Table 1, there are several materials with a short projected number of productive virgin extraction years left that are of key importance to production. There are also materials with a longer expected virgin supply such as phosphate that have a key importance to production, high lack of substitutes, and yet currently a low recyclability. Stockpiling secondary materials that include content of such materials could be a responsible high value recycling strategy.

\subsection{Economies of Scale}

Typically recycling and waste management plants operate on a scale of less than 1 million ton/year. Mining and extracting of virgin materials typically operate in a several million ton per year scale. The largest Waste to Energy plant in Sweden has a capacity of $480 \mathrm{kton} / \mathrm{year}$. Compared to virgin material, waste has a far more complex composition and hence, in general, more unit operations are needed per ton material produced; this to drives OPEX (Operational expenditure) and CAPEX (Capital expenditure). Another important issue of scale arises when selling the materials extracted as the buyer needs guarantee enough volume 
of product can be delivered. Stockpiling - or the creation of manmade deposits - is a tool to achieve enough scale to enable extraction of resources[7][8]. This is illustrated in Figure 4, in axis $V_{B}$. As long as the supply of extracted secondary materials to market is not a large percentage of total market (and prices are relatively inflexible), diseconomies of scale should not be of concern.

\section{Case of Phosphor}

As shown in in Table 1, phosphate is currently a material with a low recyclability, yet of high importance to societal production. Additionally phosphate is not easily substituted by other substances. Phosphate enters our urban systems in the form of food, feed, and industrial products[9]. It leaves in our waste water and solid waste streams, where a minor amount is returned to forestry and farming after biological or waste water treatment. However, the largest outflow is current to 'facilities' (for land construction -'plant' in the figure) and landfill[9].

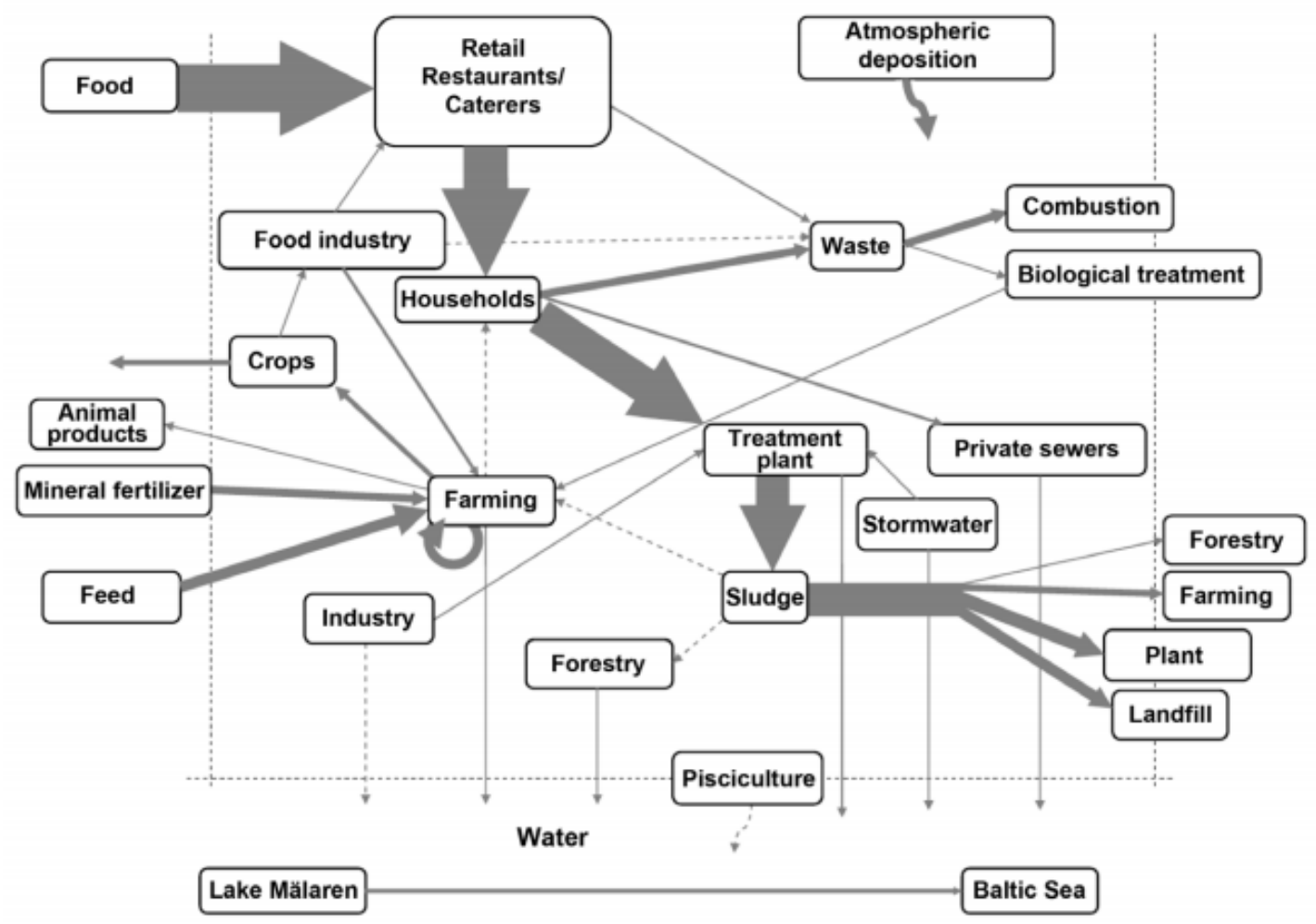

Figure 6. Phosphorus flows in Stockholm County 2009. Source: Sörenby (2010)

Instead of low value alternative uses (in mixed landfills or on non-productive facility land), perhaps stockpiling separated phosphor rich materials would a more responsible strategy. Such a strategy may require policy steering mechanisms to make it viable.

\section{Viability of alternative (low value) recycling}

Over the last twenty years waste management has changed profoundly. The major drivers for change have been several policies such as the Polluter Pays Principe[10], [11], 
sustainability[12], the waste hierarchy [13] and the common use of taxes for landfilling of waste in several countries (especially in European countries). An effect of these changes is that alternate recycling (as opposed to secondary stock extraction), may become less viable now and in the near future. This concept is explained in detail in an article by Kihl and Aid [14], and will only be synthesized here in the context of secondary stock extraction.

\subsection{Barriers to alternative recycling}

Although society has set up a number of policies, some main barriers for increased use of recycled aggregates still remain. Taking the example of the use of secondary materials in recycled aggregates some recent barriers are:

a) Legal issues - are recycled aggregates a waste or a product? If considered a waste, generally the legal process needed (permits, applications, quality control) are to slow to cope with the pace of the construction industry.

b) Economic issues - the value of the virgin material is low and the supply of recycled aggregate is low compared to demand in each construction project. For example, when a road is built the specific need will often be much greater than the possible local production of recycled aggregates.

\subsection{Risk of alternative recycling over time}

Continuing with the example of use of waste materials in recycled aggregates, a substantial issue with the continued viability of such markets is raised when assessing the risk for having to remediate such material in the future. Might such markets be spreading materials into society that will have to be painstakingly sanitized in the future? When comparing old and new clean-up levels, the following general observations can be made:

a) The number of pollutants included in the lists of clean-up levels tend to increase over time

b) The clean-up level for a specific contaminant is often reduced over time

Table 2 - The Development of general Swedish clean-up levels (not comprehensive).

\begin{tabular}{|l|c|c|c|}
\hline Pollutant & $\begin{array}{c}\text { General Swedish } \\
\text { Clean-up level, } \\
\text { Sensitive land use } \\
1996[15] \\
\mathrm{mg} / \mathrm{kg} \text { DS }\end{array}$ & $\begin{array}{c}\text { General Swedish } \\
\text { Clean-up level, } \\
\text { Sensitive land use } \\
2008 \text { [16] } \\
\mathrm{mg} / \mathrm{kg} \text { DS }\end{array}$ & $\begin{array}{c}\text { General levels } \\
\text { implying low risk if } \\
\text { used for construction } \\
\text { material, Sweden } \\
2010 \text { [17] } \\
\mathrm{mg} / \mathrm{kg} \text { DS }\end{array}$ \\
\hline Barium & No value & 200 & No value \\
\hline Benzene & 0,06 & 0,012 & No value \\
\hline Copper & 100 & 80 & 40 \\
\hline Mercury & 1 & 0,25 & 0,1 \\
\hline Zink & 350 & 250 & 120 \\
\hline
\end{tabular}


As can be seen in Table 2, the upper limit values for several substances is diminishing over time.

In a short perspective road base recycling may make sense to the producer of the waste since it's probably the most economic option (when compared to high landfill taxes) and it makes some sense for the society since natural resources may be saved. The levels of contaminants in the waste used for road base recycling may well be within what today is considered safe levels or that can be accounted for in a site specific scenario. However, in the long run, given PPP and that clean-up levels tend to be changed over time, it's likely that some of the road base recycling projects will need to be remediated in the future and that the cost for such remediation will be directed towards the Polluter. Hence, if a waste is used for road base recycling today, someone (the Polluter or Society) is taking a financial risk. This risk is rarely accounted for when comparing different options of handling waste. From the analysis above one can conclude that if recycling of waste is done the wrong way it may cause a burden for future generations, hence it may not be not a sustainable solution. It can also be concluded that there is a need for better guidance as to what wastes may be recycled for what uses.

\section{Discussion and Conclusions}

Our modern world consumes large volumes of virgin materials. The present outlook is that demand for resources such as energy, metals and minerals will increase over time due to economic growth. Though it's possible from a technical perspective to replace virgin materials by processing specific waste streams this is not viable to any large extent today. The key for saving resources in waste management is to keep focus on what kind of virgin resource can be saved (including savings on energy and materials required for extracting) when recycling - and not just finding better recycling alternatives to landfills or waste to energy per se. Some resources are more critical to society than others for several reasons. In order to achieve recycling where recycled materials can replace virgin materials the drivers and inhibitors for these markets must be known and fully understood. There are several factors to enabling competitive, viable, extraction of secondary materials for substitution of virgin materials including:

- Market value of virgin stock

- Cost of virgin and secondary stock extraction over time

- Economies of scale

- Markets for alternative recycling options

- Steering mechanisms enabling or hindering virgin, secondary, or alternative recycling markets

If industry is going to realize more responsible recycling, steering mechanisms and policy, such as landfill taxes, virgin material taxes, and permits for certain low value recycling operations should be analyzed with societies overall goals in mind.

Regarding societies overall goals for sustainability one can revisit the definition and goals set out in the Bruntland Report where, "Sustainable development is development that meets the needs of the present without compromising the ability of future generations to meet their own needs. It contains within it two key concepts: 
Linnaeus Eco-Tech'14

Kalmar, 24-26 November, Sweden

- the concept of needs, in particular the essential needs of the world's poor, to which overriding priority should be given; and

- the idea of limitations imposed by the state of technology and social organization on the environment's ability to meet present and future needs."[18]

Combining sustainable development and the knowledge of the risk for scarcity for some critical elements in the future leads us to the conclusion that it's important to change current waste management focus from "recycle everything and avoid landfills" to "replace virgin extraction of critical elements by waste and keep critical elements in the loop". We think a responsible way forward for society would be to define critical resources and find suitable steering mechanisms for those waste streams in order to prevent these resources are mismanaged today and thereby spoiled for future generations as a secondary stock. In practice this could mean promoting stockpiling rather than low grade recycling of certain types of waste streams containing significant amounts of for elements that are likely to be of concern for society in near future such as Phosphors, Potassium and Rare Earth Elements.

\section{References}

[1] Ellen MacArthur Foundation, "Report Vol. 1 - 2012 - Circular Economy Reports," 2012.

[2] V. Palm and K. Jonsson, "in Sweden Material Use for National Consumption and for Export," vol. 7, no. 1, pp. 81-92, 2003.

[3] McKinsey Global Institute, "Resource revolution: Meeting the world's energy, materials, food, and water needs," 2011.

[4] T. Norgate and N. Haque, "Energy and greenhouse gas impacts of mining and mineral processing operations," J. Clean. Prod., vol. 18, no. 3, pp. 266-274, Feb. 2010.

[5] UNEP, Environmental Risks and Challenges of Anthropogenic Metals Flows and Cycles. 2013.

[6] B. K. Reck and T. E. Graedel, "Challenges in Metal Recycling," Science (80-. )., vol. 337, no. 6095, pp. 690-695, Aug. 2012.

[7] J. M. Callan, Scott J.Thomas, "Economies of Scale and Scope: A Cost Analysis of Municipal Solid Waste Services."

[8] X. Wang, G. Gaustad, C. W. Babbitt, and K. Richa, "Economies of scale for future lithium-ion battery recycling infrastructure," Resour. Conserv. Recycl., vol. 83, pp. 53-62, Feb. 2014.

[9] L. Eckardt, “Hållbar växtnäringshantering i Stockholms län: En aktörsanalys.” 2010.

[10] OECD, "Recommendation of the Council concerning the Application of the Polluter-Pays Principle to Accidental Pollution C(89)88." 1989.

[11] OECD, "Recommendation of the council on guiding principles concerning international economic aspects of environmental policies. Council Document no. C(72)128." May-1972. 
[12] UNEP, "Rio Declaration on Environment and Development. U.N. Doc. A/CONF. 151/5/Rev.1." 1992.

[13] European Commission, "Directive 2008/98/EC of the European Parliament and of the Council of 19 November 2008 on waste and repealing certain Directives Text with EEA relevance." 2008.

[14] A. Kihl and G. Aid, "Today's Recycling into Construction Materials -The Creation of Tomorrow's Remediation Projects?," in Linnaeus ECO-TECH 2012, 2012, pp. 3-8.

[15] Swedish EPA, "Guideline values for contaminated land. In Swedish. Riktvärden för förorenad mark. Swedish EPA Report 4638," 1996.

[16] Swedish EPA, "National general clean-up levels for Sweden. In Swedish. Tabell över generella riktvärden för förorenad mark. Swedish EPA Homepage.," 2008. [Online]. Available: http://www.naturvardsverket.se/sv/Start/Verksamheter-med-miljopaverkan/Fororenadeomraden/Att-utreda-och-efterbehandla-fororenade-omraden/Riktvarden-for-fororenadmark/Tabell-over-generella-riktvarden/. [Accessed: 05-Nov-2012].

[17] Swedish EPA, "Recycling of waste in facility works. In Swedish. Återvinning av avfall i anläggningsarbeten, Handbok. Swedish EPA document 2010:1," 2010.

[18] World Commission On Environment and Development, Our Common Future. Oxford University Press, USA, 1987, p. 400. 